\title{
UPDATED ADVICE ON FEEDING BABIES IN THE FIRST YEAR OF LIFE
}

Scientific Advisory Committee on Nutrition (SACN) has published its report on Feeding in the First Year of Life (1) providing recommendations on infant feeding from birth up to 12 months of age.

The last review of infant feeding was undertaken by SACN's predecessor Committee on Medical Aspects of Food Policy (COMA) in 1994 and formed the basis for government recommendations in the UK.

SACN recommends babies are exclusively breastfed until around 6 months of age and continue to be breastfed for at least the first year of life. Additionally, solid foods should not be introduced until around 6 months to benefit the child's overall health. This represents no change to current government recommendations. SACN concludes breastfeeding makes an important contribution to infant and maternal health. This includes the development of the infant immune system, while not breastfeeding is associated with a higher risk of infant hospital admission for infectious illness.

By around 6 months of age, infants are usually ready to accept foods other than breastmilk or formula. SACN concludes delaying solid foods to around 6 months is not associated with later difficulty in accepting solid foods - the idea of a 'critical window' between 4 and 6 months is not supported by the evidence.

SACN has recommended strengthening advice regarding the introduction of peanuts and hen's egg - advice on complementary feeding should state these foods can be introduced from around 6 months of age and need not be differentiated from other solid foods. The deliberate exclusion of peanuts or hen's egg beyond 6 to 12 months of age may increase the risk of allergy to these foods.

The report has been welcomed by the British Society of Paediatric Dentistry. Professor Emeritus Andrew Rugg-Gunn, BSPD's expert and a former member of the SACN panel, commented: 'I welcome this report and the inclusion of the chapter on oral health, rightly emphasising its importance in the general development of infants.'

'Both BSPD and I were delighted to have been given the opportunity to provide input, ensuring that this document is representative and that all concerned with children's oral health can speak with one voice'.

'It's valuable for all organisations working in the interests of children's health to be aware that long-term and on demand breast feeding may be a risk factor for Early Childhood Caries, as highlighted in this report and in our own position statement (2). More research is needed and we look forward to further guidance from SACN on feeding children after the age of one.'

Other recommendations in the report include:

- breast milk, infant formula and water

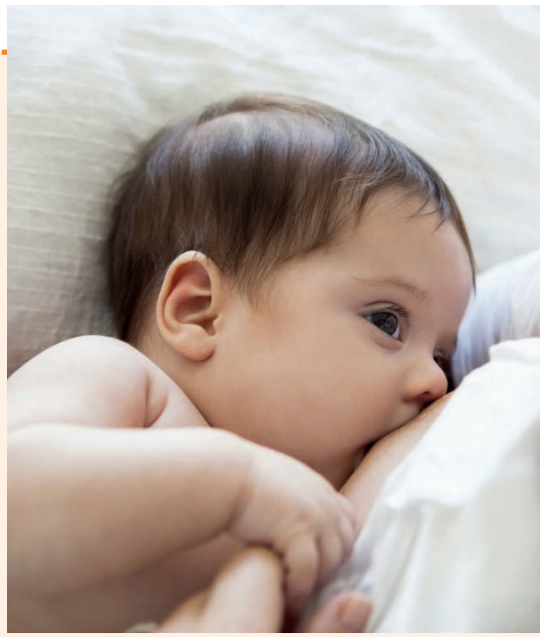

should be the only drinks offered between 6 and 12 months of age - cows' milk should not be given as a main drink, as this is associated with lower iron status

- a wide range of solid foods, including foods containing iron, should be introduced from around 6 months of age, alongside breastfeeding - these foods should have different textures and flavours and may need to be tried several times before the infant accepts them, particularly as they get older

- breastfed infants up to 12 months should receive a daily supplement containing 8.5 to $10 \mu \mathrm{g}$ of vitamin D (340-400 IU/d) - formula-fed infants do not need a supplement unless consuming less than $500 \mathrm{ml}$ of infant formula a day

1. https://www.gov.uk/government/ publications/feeding-in-the-first-year-oflife-sacn-report

2. https://www.bspd.co.uk/Resources/ Position-Statement

\section{Dental Thygenius' Thish Maitland an inspiration}

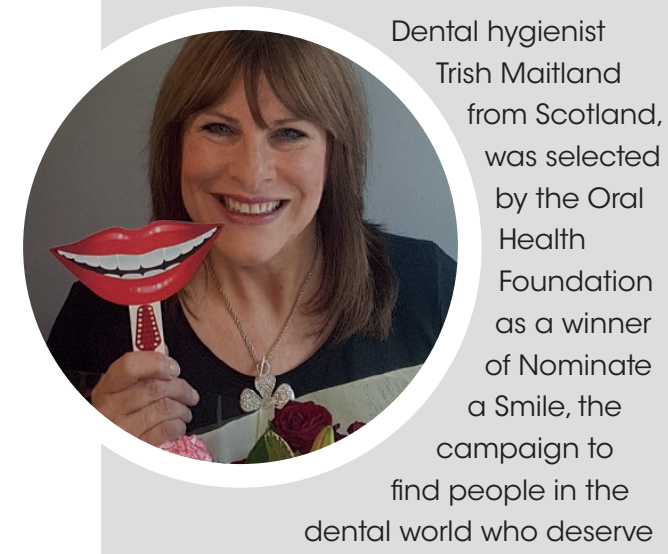

recognition for their positive impact on the community.

Trish, who works at Dental Inspirations in Stonehaven near Aberdeen, was nominated for the award by her practice manger Leianna Minty, who labelled her as a 'HyGenius' before saying she has one of the 'warmest smiles that would ever greet you.'

Speaking of Trish, Leianna says: 'Nothing is too much for her, she goes above and beyond for all her patients and really just anyone she comes into contact with. Trish is dedicated, genuine and has a true heart of gold. I could list thing after thing about our Trish and why she should win, but mostly because she is her and we love her.'

In the nomination, Leianna goes into detail about how Trish makes time to help raise money for charities despite providing care for her son with Cystic Fibrosis 'Trish has various things going on with her personal life, giving love and assistance to her family, especially her son and elderly parents, but she still makes time for charity work both within the practice and personally. Even on her days off she volunteers at care homes.'

The Nominate a Smile competition was a key part of National Smile Month, a charity campaign to promote good oral health, and sets out to find very special people with smiles that have the power to lift all those around them. 